\title{
Fungal parasites of the green alga Chaetomorpha media
}

\author{
Chandralata Raghukumar
}

Biological Oceanography Division, National Institute of Oceanography, Dona Paula, Goa 403004 , India

\begin{abstract}
Green alga Chaetomorpha media (C. Agardh) Kützing, collected from intertidal beaches in Goa, was found to be infected with the fungi Pontisma lagenidioides Petersen and Labyrinthula sp. Approximately $5 \%$ of the alga was infected by these fungi in nature. Inoculation of healthy alga by the fungi in the laboratory resulted in severe infection and whole plants were destroyed in 12 to $15 \mathrm{~d}$. The severity of diseases was measured in terms of percentage of diseased cells and loss in fresh weight. Maximum infection occurred at salinities of 30 and $35 \%$. Infection was greater when the algal cultures were aerated. Culturing of Labyninthula sp. in the laboratory is also reported.
\end{abstract}

\section{INTRODUCTION}

Although fungal diseases of marine algae have been reported (Kazama \& Fuller 1970, Schnepf et al. 1978, Van Der Meer \& Pueschel 1985, Molina 1986) most of these studies have concentrated on the taxonomy and development of the fungi concerned. Laboratory experiments to study the physiology and pathology have been few (C. Raghukumar 1978, 1983, Bott \& Rogenmuser 1980).

Several fungal diseases of marine algae have been reported from Indian waters (C. Raghukumar $1986 \mathrm{a}, \mathrm{b}$, $c$ [preceding article] 1987). Among these are the browning disease of the filamentous green alga Chaetomorpha media (C. Agardh) Kützing, caused by Pontisma lagenidioides Petersen, and disease caused by the protist Labyrinthula sp. Both diseases were reported from the Mandapam waters of southern India (C. Raghukumar 1987). C. media also occurs abundantly on rocky beaches in Goa on the west coast of India. During a survey of algal pathogens, both the above mentioned parasites were found to occur in this alga from both regions. Both the parasites could be maintained easily in the laboratory in co-culture with the alga, enabling a detailed study of the disease.

This article reports laboratory findings on Chaetomorpha media and its pathogens from Goan beaches.

\section{MATERIALS AND METHODS}

Chaetomorpha media was collected from intertidal rocks during low tides from Baga, Arambol and Anjuna beaches in Goa. Care was taken not to damage the specimens during collection. Specimens were transported in seawater to the laboratory, where they were thoroughly cleaned and incubated in sterile seawater. Sterile seawater without added nutrients was replaced daily for the first week after collection and thereafter every $5 \mathrm{~d}$. These samples were inspected every day under a stereo-microscope and light microscope for the fungal pathogens Pontisma lagenidioides and Labyrinthula sp. Whenever these pathogens were present, incubation of algal material in sterile seawater resulted in infection of almost all the algal filaments in about $10 \mathrm{~d}$. Such infected filaments were used as inoculum material for all the experiments. The algal material from Baga and Arambol beaches in Goa revealed infection by these fungi, whereas the material from Anjuna beach was always totally free from these pathogens. Therefore samples from this site were used for diseasefree material.

For studying disease symptoms and disease severity under controlled laboratory conditions, freshly collected pathogen-free plants of Chaetomorpha media from Anjuna were carefully washed with sterile seawater and co-cultured with an infected filament 
(obtained as mentioned above) of C.media. One infected filament was used per plant. Disease severity was expressed as the percentage of infection based on the total number of infected cells in 2 plants. A mature plant of C.media has about 40 to 60 filaments. Each filament has about 100 to 170 cells. A total of 20 filaments from 2 plants were counted to assess the severity of infection.

Disease severity was also measured by comparing the loss in fresh weight of inoculated and uninoculated plants. Five replicates, each containing 2 plants of similar sizes, were inoculated with 2 infected filaments. The control plants were incubated without any addition of infected material. The loss in fresh weight was calculated from Day 0 to Day 15 at 3 d intervals. The plants were blotted before being weighed and afterwards immediately put back into sterile seawater. Results are expressed as percentage weight loss in healthy as well as inoculated plants with reference to the initial weight on Day 0. A Students t-test was employed to determine the significance of final loss in fresh weight between healthy and inoculated plants.

The influence of salinity on disease severity was studied by incubating plants in sterile seawater adjusted to salinities of $10,15,20,25,30$ and $35 \%$, and inoculated as above. Disease severity was calculated as percentage of cells infected after $7 \mathrm{~d}$.

To determine the effect of aeration and agitation, 5 plants of Chaetomorpha media were incubated in sterile seawater and aerated continuously, while another set of 5 plants was not aerated. Each set was inoculated by adding 5 infected filaments. Control plants without any addition of infected material were also similarly maintained in 2 series (aerated and non-aerated). All the sets received fresh sterile seawater everyday. The number of infected cells in 5 plants ( 2 filaments counted from each plant) was counted randomly at $3 \mathrm{~d}$ intervals for $15 \mathrm{~d}$ and the results expressed as percent infection of plants. Loss in wet weight of 5 plants from Day 0 to Day 15 , at $3 \mathrm{~d}$ intervals, was measured in a parallel experiment and the results expressed as a percent loss in wet weight. A Student's t-test was employed to determine the significance of differences between the 2 treatments - aerated and non-aerated - on the final day of the experiment (Day 15).

\section{RESULTS}

As seen from Fig. 1 more than $30 \%$ of Chaetomorpha media was infected by the fungus Pontisma lagenidioides on Day 3 and by Day 15 about $90 \%$ of cells were infected. As the disease progressed, the inoculated plants lost their turgidity and became limp. This was best observed by measuring the loss in wet

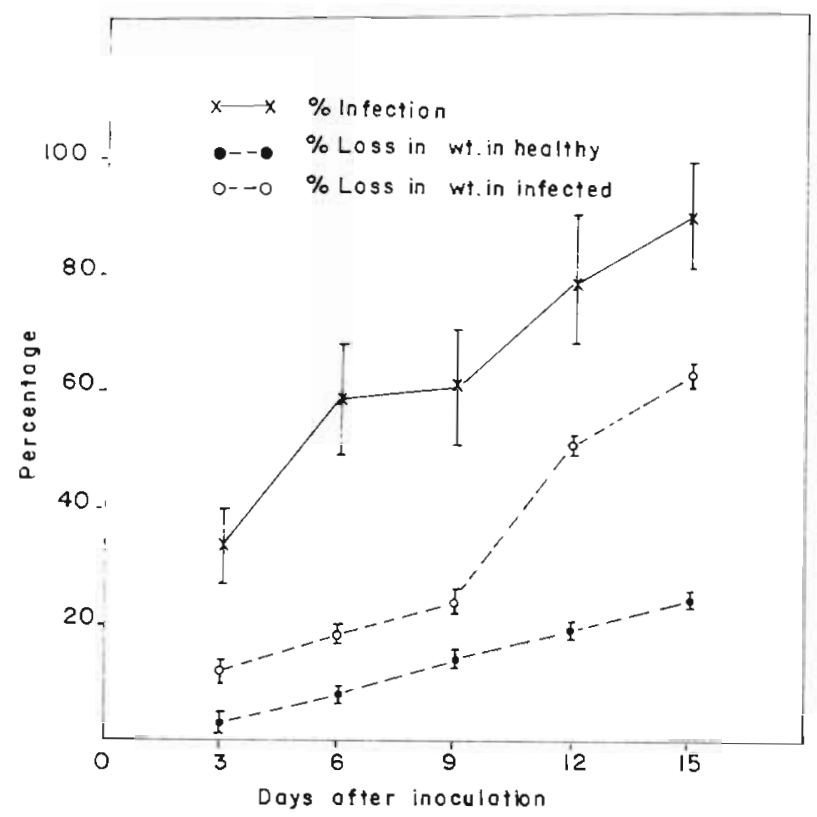

Fig. 1. Chaetomorpha media infected by Pontisma lagenidioides. Percentage of infection and percent loss in wet weight. Bar represents standard deviation

weight. The uninoculated as well as inoculated plants showed loss in weight. However, the rate of loss of weight in inoculated material was much higher (Fig. 1). About $63 \%$ loss in wet weight was observed in inoculated plants, nearly 3 times higher than in control plants. The results were significant at the $0.1 \%$ level (d. f. $=6$ ).

Younger plants were comparatively less susceptible to infection than older plants. Salinity influenced the severity of the disease, as it was observed that maximum infection occurred at and above $30 \%$ salinity (Table 1) while no infection could be observed below $20 \%$ salinity. Chaetomorpha media, however, survived at all salinities tested.

Plants kept under aeration showed a slightly higher percentage of infection than non-aerated plants (Fig. 2). These results were significant at the $5 \%$ level (d.f. $=18$ ). However, the percent loss in wet weight between aerated and non-aerated cultures (Fig. 3) was not significantly different ( 75 and $73 \%$ respectively).

Table 1. Chaetomorpha media infected by Pontisma lagenidioides. Influence of seawater salinity on infection

\begin{tabular}{|cc|}
\hline Salinity $(\%)$ & $\%$ infection of cells \\
\hline 35 & 100 \\
30 & 100 \\
25 & 66 \\
20 & 8 \\
15 & 0 \\
10 & 0 \\
\hline
\end{tabular}


About $60 \%$ of Chaetomorpha media cells became infected with Labyrinthula sp. by Day 15 (Fig. 4). Both healthy and infected plants showed loss of weight on incubation in seawater (Fig. 4). However, the percent

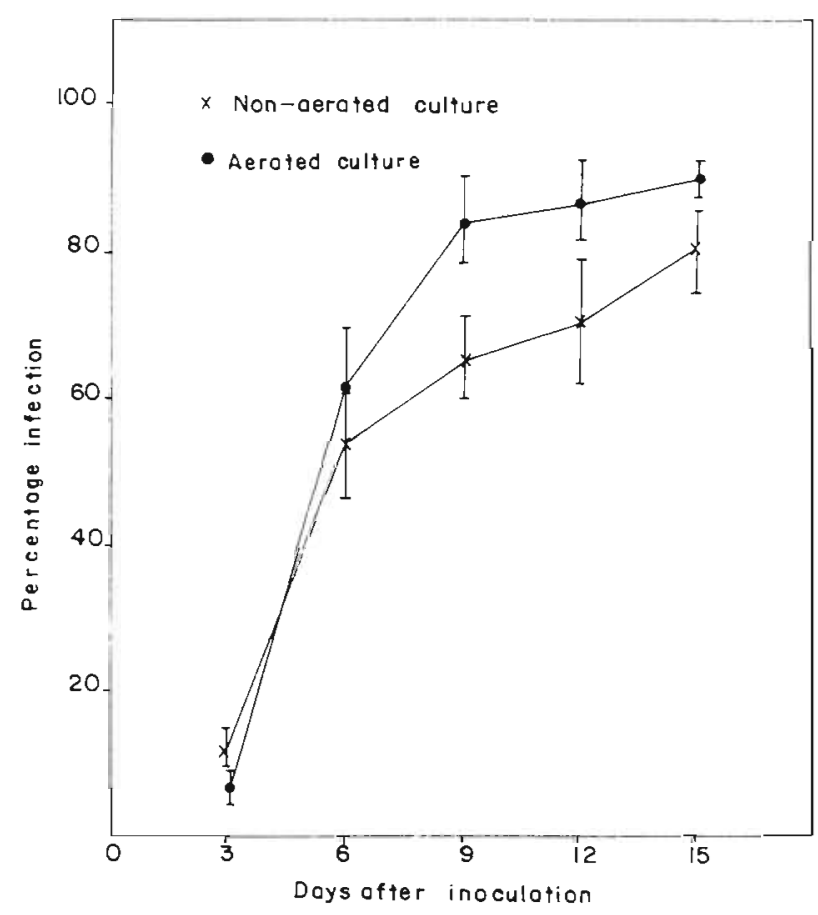

Fig. 2. Chaetomorpha media infected by Pontisma lagenidioides. Percent infection in aerated and non-aerated cultures. Bar represents standard deviation loss in wet weight of infected plants (Fig. 4) was 3 times that of healthy plants. These results were significant at the $0.1 \%$ level (d.f. $=8$ ).

The fungus Pontisma lagenidioides could not be cultured on artificial media or on killed Chaetomorpha media filaments. Labyrinthula sp. was cultured on autoclaved filaments of C.media. This culture could successfully establish infection in healthy and living C. media plants.

\section{DISCUSSION}

Even freshly collected Chaetomorpha media showed infection up to $5 \%$ by the fungus Pontisma lagenidioides. Infection proved devastating under laboratory conditions killing all the plants within 10 to $12 \mathrm{~d}$. However, $P$. lagenidioides did not survive when the alga died out. The fungus could not be cultured either on artificial media or on killed host alga and hence is an obligate parasite. Therefore attempts at culturing this fungus could be extremely rewarding as it could be tried out in biological control of C. media, which is one of the major fouling algae (Anonymous 1980). On the other hand, Labyrinthula sp. could be cultured on autoclaved filaments of $C$. media. It also was capable of parasitising the living green alga.

Many members of the Mastigomycotinae which are obligate parasites have been maintained in the laboratory as dual cultures where the host alga is freshly

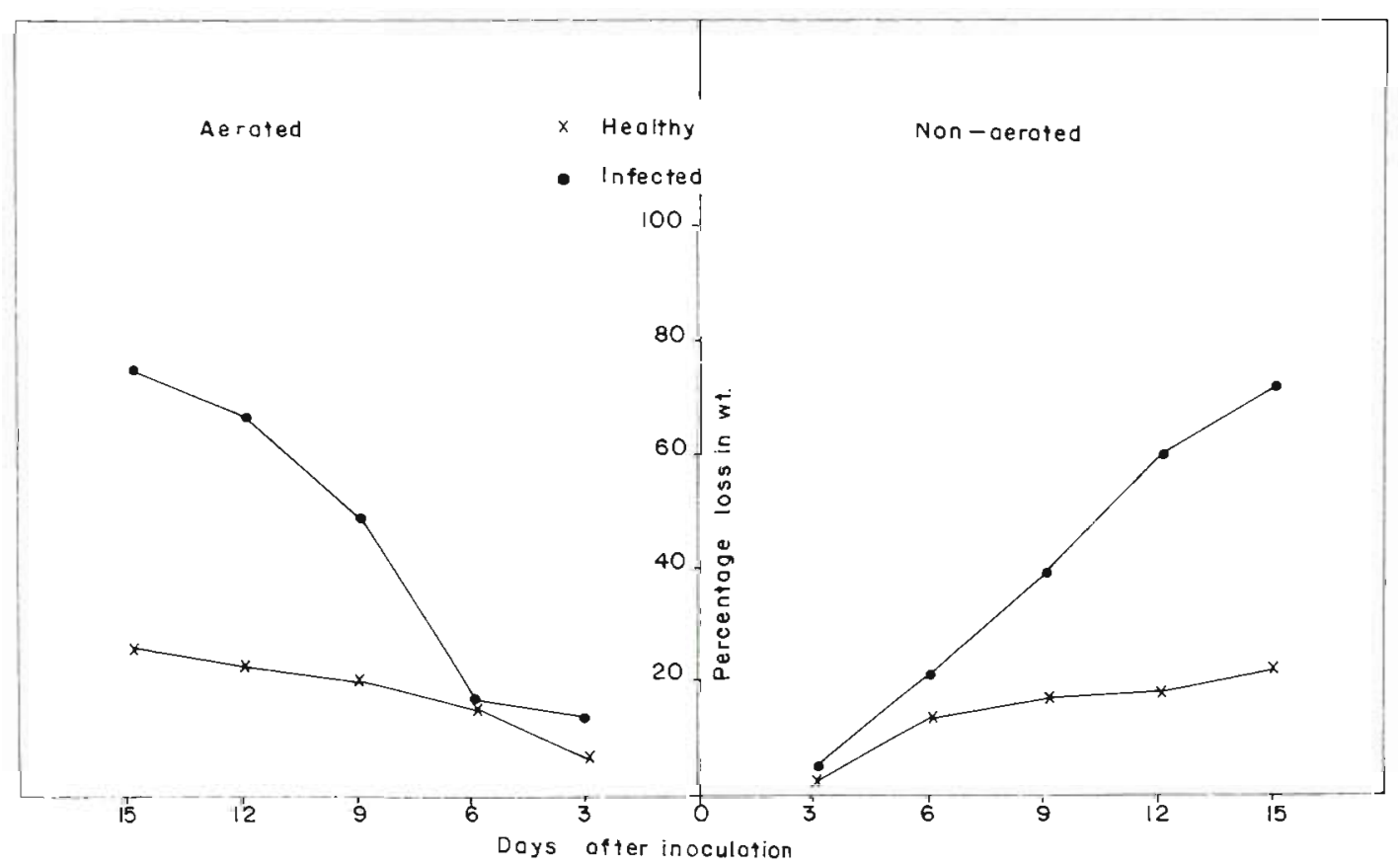

Fig. 3. Chaetomorpha media infected by Pontisma lagenidioides. Percent loss in wet weight in aerated and non-aerated cultures. Note reversed scale to the left 


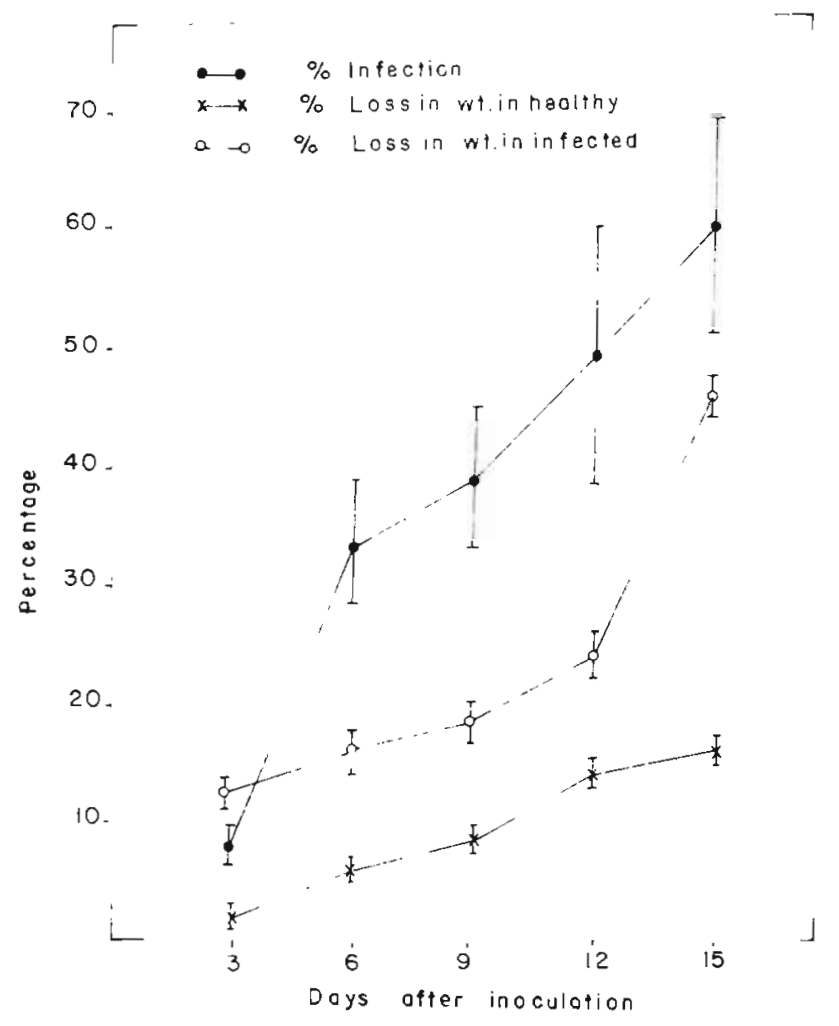

Fig. 4. Chaetomorpha media infected by Labyrinthula sp. Percentage of infection and percent loss in wet weight. Bar represents standard deviation

inoculated with its pathogen at regular intervals (Raghukumar 1978, Schnepf et al. 1978, Van Der Meer \& Pueschel 1985, Molina 1986).

The percentage of cells infected with Pontisma lagenidioides in Chaetomorpha media increased from Day 0 to 15. Simultaneously browning of the filaments also increased as more and more cells were infected with further progress of the disease. The biomass of the alga was very much affected by these pathogenic fungi as can be seen by the percentage loss in wet weight of infected samples. Loss in dry weight and browning of the alga as a measure of disease severity has been used in studies on Cladophora glomerata infected by the fungus Acremonium kiliense Grütz (Bott \& Rogenmuser 1980) under laboratory conditions.

Disease severity by Pontisma lagenidioides was greater in aerated cultures of Chaetomorpha media. Agitation probably provided better transport of zoospores to infection sites.
Pontisma lagenidioides and Labyrinthula sp. might be widespread pathogens of Chaetomorpha media, occurring on both the west and east coast of India. However, the absence of these pathogens on the alga from one locality in Goa (Anjuna beach) is very interesting and perhaps local physico-chemical factors further influence the occurrence of these pathogens.

Acknowledgements. I thank Dr S. Raghukumar for critically reading the manuscript. I also thank an anonymous referee for many valuable suggestions

\section{LITERATURE CITED}

Anonymous (1980). Catalogue of main marine fouling organisms, Vol. VI, Algae. Office d'Etudes Marines et Atmospheriques ODEMA, Bruxelles, Belgium.

Bott, T. L., Rogenmuser, K. (1980). Fungal pathogens of Cladophora glomerata (Chlorophyta). Appl. environ. Microbiol. 40: 977-980

Kazama, F., Fuller, M.S. (1970). Ultrastructure of Porphyra perforata infected with Pythium marinum, a marine fungus. Can. J. Bot. 48: 2103-2107

Molina, F. I. (1986). Petersenia pollagaster (Oomycetes): an invasive fungal pathogen of Chondrus crispus (Rhodophyceae). In: Moss, S.T (ed.) The biology of marine fungi. Cambridge Univ. Press, Cambridge, p. 165-175

Raghukumar, C. (1978). Physiology of infection of the marine diatom Licmophora sp. by the fungus Ectrogella perforans. Veröff. Inst. Meeresforsch. Bremerhaven 17: 1-14

Raghukumar, C. (1983). Resistance mechanism in LiCmophora, a marine diatom, against infection by the fungus Ectrogella perforans. Veröff. Inst. Meeresforsch Bremerhaven 19: 185-190

Raghukumar, C. (1986a). Chytridium polysiphoniae - a fungal pathogen on the red alga, Centroceras clavulatum (C. Agardh) Montagne, from Goa. Indian J. mar. Sci. 15: 42-44

Raghukumar, C. (1986b). Thraustochytrid fungi associated with marine algae. Indian J. mar. Sci. 15: 121-122

Raghukumar, C. (1986c). Fungal parasites of the marine green algae, Cladophora and Rhizoclonium. Botanica mar. 29: 289-297

Raghukumar, C. (1987). Fungal parasites of marine algae from Mandapam (South India). Dis. aquat. Org. 3: 137-145

Schnepf, E., Deichgräber, G., Drebes, G. (1978). Development and ultrastructure of the marine, parasitic oomycete, Lagenisma coscinodisci Drebes (Lagenidiales). Thallus, zoosporangium, mitosis and meiosis. Arch. Mikrobiol. 116: $141-150$

Van Der Meer, J.P. Pueschel, C.M. (1985). Petersenia palmariae n. sp. (Oomycetes): a pathogenic parasite of the red alga Palmaria mollis (Rhodophyceae). Can. J. Bot. 63: $404-408$ 